\title{
DOCENCIA UNIVERSITÁRIA: UM ESTUDO SOBRE A INTERAÇÃO ENTRE DOCENTES E ESTUDANTES EM CURSOS NA MODALIDADE SEMIPRESENCIAL
}

\author{
(UNIVERSITY TEACHING: A STUDY ON THE INTERACTION BETWEEN \\ TEACHERS AND STUDENTS IN THE COURSE TYPE SEMIPRESENTIAL)
}

Walteno Martins Parreira Júnior

Silvana Malusá Baraúna

Guilherme Saramago de Oliveira

Universidade Federal de Uberlândia, UFU (Brasil)

\section{RESUMO}

Este trabalho apresenta os resultados de uma pesquisa sobre docência universitária a distância, em cursos de formação de professores que adotam a modalidade semipresencial. O objetivo foi o de compreender como ocorre o olhar do professor universitário sobre sua prática pedagógica, específicamente sobre a interação entre professor e aluno neste cotidiano. Utilizou-se como instrumento de pesquisa um questionário, construído nas abordagens quantitativa e qualitativa, composto por três partes: identificação/qualificação docente, conteúdo programático e questões abertas. Os docentes atuam em dois cursos de uma Instituição do Ensino Superior do Triângulo Mineiro, Minas Gerais. Os resultados constataram que estes profissionais fazem uso das Tecnologias de Informação e Comunicação - TIC - no processo de ensino-aprendizagem, para interação, organização, desenvolvimento de conteúdos programáticos e atividades de avaliação.

Palavras-chave: docência universitária a distância, prática didático-pedagógica, ensino semipresencial.

\begin{abstract}
This study, presents the results of an investigation into the university pedagogical practices of professors who adopt the semipresential modality in education teaching courses. The aim was to understand how this professional looks upon his own practice, specifically on the interaction between teacher and student in daily life. As a survey instrument, it was used a questionnaire, built on quantitative and qualitative approaches, consisting of three parts: identification / teaching qualification, syllabus and open questions. The teachers work in two courses of a Higher Education Institution in the Triângulo Mineiro, in Minas Gerais State. The results showed that these professionals make use of Information and Communication
\end{abstract}


Technologies -ICTs - in the process of teaching and learning, for interaction, organization, development of syllabuses and evaluating activities.

Keywords: university distance teaching; Didactic and pedagogical practice; Semipresential teaching.

A finalidade deste trabalho é apresentar os resultados de pesquisa desenvolvida com um grupo de professores universitários cujo tema é a docência a distância e a prática do docente que atua com disciplina semipresencial e a distância em cursos de graduação de formação de professores na modalidade presencial. O objetivo é compreender, através de entrevistas com os docentes que atuam nesses cursos, qual o olhar sobre a própria prática didático-pedagógica, com ênfase na interação entre docentes e estudantes. Espera-se chegar a um entendimento mais completo sobre como o docente faz uso das Tecnologias da Informação e Comunicação (TIC) no processo ensino-aprendizagem e entender a relação dele com esses recursos na prática cotidiana da sala de aula virtual. "É recomendável que as instituições elaborem seus materiais para uso a distância, buscando integrar as diferentes mídias, explorando a convergência e integração entre materiais impressos, radiofônicos, televisivos, de informática, de videoconferências e teleconferências, dentre outros, sempre na perspectiva da construção do conhecimento e favorecendo a interação entre os múltiplos atores" (Brasil, 2007, p.15).

O progresso das TICs exige do docente um esforço para compreender as oportunidades e o funcionamento desses instrumentos. Com a disponibilidade dos recursos digitais, novas oportunidades para o cotidiano da educação a distância podem ser utilizadas na interação professor-aluno.

Uma parcela significativa dos estudantes possuem acesso às TIC e estão habituados a utilizá-las para se comunicar ou informar. E considerando que esse é um fato irreversível, observa-se que são os docentes que necessitam de capacitação e incentivo para a utilização desses recursos em sala de aula e também em seu cotidiano. Tanto é que muitas escolas já utilizam blogs, vídeos, hiperlinks, chats e $e$-mails, entre outros, e exigem, cada vez mais, a qualificação de seus professores nesse sentido para que complementem as atividades cotidianas das disciplinas que lecionam, sejam elas presenciais ou a distância.

Este trabalho é desenvolvido como uma pesquisa aplicada, exploratória, de abordagem quantitativa e qualitativa e do tipo estudo de caso. Essa definição foi adotada devido à natureza do objeto de pesquisa ser as práticas didáticas de um grupo de professores de curso de graduação presencial em uma IES onde lecionam 
disciplinas semipresenciais. "Na modalidade semipresencial, estudantes e professores estão separados fisicamente em determinados momentos da disciplina, mas interligados por meio das tecnologias de comunicação e interação e dos materiais didáticos empregados. Por tais especificidades, a semipresencialidade torna-se um elemento a mais de flexibilização curricular, no que diz respeito às condições individuais de cada estudante, ao ritmo de aprendizagem, ao local e ao tempo de dedicação aos estudos" (Marchi, Araújo y Istreit, 2008, p. 2).

Para Moroz e Gianfaldoni (2003, p. 16) “o conhecimento científico é um processo de busca de respostas", e tem como objetivo encontrar "explicações sobre a realidade, sendo possível tanto preencher lacunas num determinado sistema explicativo vigente num momento histórico quanto colocar em xeque dado sistema”.

Para Goldenberg (1997, p. 62) a utilização de diferentes abordagens de pesquisa contribui para a análise de diversas questões, ou seja, "o conjunto de diferentes pontos de vista, e diferentes maneiras de coletar e analisar dados (qualitativa e quantitativamente), que permitem uma idéia (sic) mais ampla e inteligível da complexidade de um problema. A maior parte dos pesquisadores em ciências sociais admite, atualmente, que não há uma única técnica, um único meio válido de coletar os dados em todas as pesquisas. Acreditam que há uma interdependência entre os aspectos quantificáveis e a vivência da realidade objetiva no cotidiano”.

Na instituição escolhida para este estudo há 33 docentes atuando nos cursos de Pedagogia e Química. Desse total, foram selecionados, para a aplicação do instrumento de pesquisa, 13 docentes que ministram as disciplinas oferecidas no regime semipresencial.

Esses cursos são ofertados no período noturno e em regime anual. $\mathrm{O}$ aluno frequenta a maioria das disciplinas presencialmente e, em cada série, há duas ou três delas que são ministradas na modalidade semipresencial. Esse modelo educacional está contemplado na Portaria Ministerial 4.059/2004, onde define que cursos já reconhecidos podem ofertar até $20 \%$ de sua carga horária a distância. Essas disciplinas são desenvolvidas de forma que parte da carga horária delas é ministrada presencialmente e a outra parte - de 33\% até $75 \%$ - a distância. "Através da Portaria 4.059, o Ministério da Educação autorizou a implementação da semipresencialidade nos cursos de graduação reconhecidos das instituições de ensino superior. Os cursos de graduação que desejam ofertar disciplinas na modalidade semipresencial devem regulamentá-las nos projetos pedagógicos, respeitando o limite de 20\% (vinte por cento) da carga horária prevista para a integralização curricular" (Marchi, Araújo e Istreit, 2008, p.1-2). 
O instrumento de pesquisa foi aprovado pelo Comitê de Ética em Pesquisas com Seres Humanos da UFU conforme parecer $n^{0}$. 638/11 dessa instituição.

A primeira parte, denominada de "Dados gerais sobre o sujeito pesquisado" contém um conjunto de informações sobre: sexo, faixa etária, titulação/ano de conclusão, tempo de magistério superior, tempo que ministra disciplina no semipresencial, formação para EAD.

A segunda parte, denominada "Categorias a serem estudadas", foi estruturada a partir de quatro (4) categorias selecionadas no documento intitulado "Referenciais de Qualidade para Educação Superior a Distância” publicado pelo MEC: Uso da Tecnologia da Informação e Comunicação (TICs) no processo ensino-aprendizagem, Qualidade do material didático institucional impresso (ou em outro formato), Efetividade na utilização dos mecanismos gerais de interação entre docentes, tutores e estudantes e, por último, Coerência dos procedimentos de avaliação dos processos de ensino-aprendizagem com a concepção do curso na modalidade EAD. "As categorias são empregadas para se estabelecer classificações. Nesse sentido, trabalhar com elas significa agrupar elementos, idéias ou expressões em torno de um conceito capaz de abranger tudo isso. Esse tipo de procedimento, de um modo geral, pode ser utilizado em qualquer tipo de análise em pesquisa qualitativa" (Gomes, 1994, p. 70).

Cada uma dessas categorias apresenta sete (7) frases afirmativas, às quais deverão ser atribuídos valores, por parte de cada sujeito participante desta pesquisa, dentro da escala Likert de cinco pontos. "A escala likert é uma escala amplamente utilizada que exige que seus entrevistados indiquem um grau de concordância ou discordância com cada uma de uma série de afirmações sobre o objeto de estímulo. Tipicamente, cada item da escala tem cinco categorias de resposta, que vão de discordo totalmente a concordo totalmente" (Malhotra, 2004, p. 266, grifo do autor).

A terceira parte do instrumento de pesquisa "Comentários" trata-se de um questionamento apresentado ao Sujeito com a seguinte indagação "Como você, professor universitário, que ministra disciplinas a distância, pensa, elabora, implementa e avalia a sua avaliação presencial?”. É um espaço aberto para que cada sujeito possa expressar sua opinião sobre um tema importante no contexto pesquisado, que é a Avaliação presencial de que o aluno de disciplinas a distância são obrigados a participar por imposição legal.

Neste trabalho está sendo abordada a categoria "efetividade na utilização dos mecanismos gerais de interação entre docentes, tutores e estudantes”. 


\section{A DOCÊNCIA UNIVERSITÁRIA}

A docência universitária é exercida por um bacharel ou licenciado na área de conhecimento da disciplina que ministra. Segundo Malusá e Silva (2007, p. 207), a formação de docentes para o ensino superior não está regulamentada de forma específica, requerendo apenas que seja preparada em cursos de pós-graduação.

Ao considerar que a atividade docente universitária é complexa e influenciada por ações externas e por concepções internas do profissional docente, percebese a existência de um conjunto de características que devem ser analisadas para se entender a sua atuação enquanto docente. Escreve Cicillini (2010, p. 30) que existem muitas discussões sobre a formação de professores universitários quanto aos "saberes que são necessários para atender à demanda encontrada no interior da universidade, no que diz respeito a formar e a continuar se informando/formando na profissão".

O profissional docente é o resultado de sua formação, de sua experiência de vida e profissional, das trocas de conhecimentos com seus pares, de suas interações sociais e das oportunidades de aprendizado que teve ao longo de sua carreira.

Para o professor que assume a docência a distância, além dos seus conhecimentos científicos e didáticos é também necessário o domínio de recursos tecnológicos que são indispensáveis para o seu cotidiano. Como escrevem Maia e Mattar (2007, p. 90), a educação a distância abre novas funções a serem desempenhadas, então novas possibilidades de trabalho estão disponíveis, "justamente pelo fato de ele não exercer mais a sua profissão como antigamente". "A experiência do ensino a distância demonstrou que, no nível do ensino superior, uma dose sensata de utilização dos meios de comunicação social, de cursos por correspondência, de tecnologias de comunicação informatizadas e de contatos pessoais, pode ampliar as possibilidades oferecidas, a um custo relativamente baixo" (Delors et al., 1998, p. 144).

Segundo Delors et al. (1998, p. 152), a contribuição dos professores para o desenvolvimento das sociedades no século XXI será crucial, com a finalidade de preparar os jovens para encarar o futuro com confiança e também de maneira responsável. Assim, os professores têm papel determinante na formação do aluno e com as atitudes dele perante aos estudos, devendo despertar-lhe a curiosidade, a autonomia, o rigor intelectual, além de criar-lhe as condições para o sucesso da educação formal e permanente. 
O trabalho do professor não consiste simplesmente na transmissão de informações ou conhecimentos, mas sim de apresentá-los na forma de problemas, situando-os em um contexto e na perspectiva com a qual o aluno possa estabelecer a ligação entre a solução deles e de outras situações análogas (Delors et al., 1998, p. 157). "A forte relação estabelecida entre professor e aluno constitui o cerne do processo pedagógico. $\mathrm{O}$ saber pode evidentemente adquirir-se de diversas maneiras e o ensino a distância ou a utilização de novas tecnologias no contexto escolar têmse revelado eficazes. Mas para quase todos os alunos, em especial para os que não dominam ainda os processos de reflexão e de aprendizagem, o professor continua indispensável” (Delors et al., 1998, p. 156).

Segundo Nóvoa (2008, p. 229), o trabalho docente depende da participação do discente, posto que ninguém ensina a quem não quer aprender. E complementa afirmando que "o problema se torna mais complicado se considerarmos as circunstâncias da presença do aluno, que não é produto de um ato de vontade, mas antes, de uma obrigação social e familiar”.

Nóvoa (2008, p. 232), citando Labaree (2000), escreve que o "bom docente é aquele que se torna não-indispensável”, que faz com que seus alunos aprendam de forma autônoma, sem a sua ajuda. E complementa que é esse um dos dilemas "mais sublimes da profissão docente".

Lessard e Tardif (2008, p. 268) escrevem que as TICs são inevitáveis e os docentes devem aprender a utilizá-las para fins pedagógicos, e assim transformar o papel do docente, "deslocando o seu centro, da transmissão dos conhecimentos para a assimilação e a incorporação destes pelos alunos, cada vez mais competentes para realizar de maneira autônoma tarefas e aprendizagens complexas".

Neste contexto de transformação e de novas exigências em relação ao ensinar e aprender, as mudanças prementes não dizem respeito à adoção de métodos diversificados, mas sim à atitude diante do conhecimento e da aprendizagem, bem como a uma nova concepção de homem, de mundo e de sociedade. Isso implica que o professor terá papéis diferentes a desempenhar, fazendo-se necessários novos modos de formação que possam prepará-lo para o uso pedagógico do computador. "A entrada de novas tecnologias no ambiente escolar traz uma nova dimensão à práxis educacional. Isso porque a sociedade atual, também chamada de Sociedade da Informação, sofre mudanças radicais nas relações econômicas, políticas, sociais e culturais. Neste contexto, o processo educacional tenta fazer uma ponte entre o modelo tradicional das escolas regulares, que passa por transformações, e esse grande avanço da tecnologia" (Barros, 2009, p. 2). 
Usar o computador como uma ferramenta de apoio no processo ensinoaprendizagem é transformar a relação já existente entre educador e aluno, permitindo o uso de TICs, tanto em sala de aula tradicional quanto nas atividades de pesquisa e complementação dos estudos fora dela, estimulando o discente a buscar novas informações e a construir o seu próprio conhecimento. "O resultado é um modelo educacional que pode ser eficiente, em que o professor torna-se um orientador no processo ensino-aprendizagem do aluno. Em outras palavras, o mestre, detentor do saber, deixa de existir, dando lugar a um companheiro de novas descobertas, significando dar ao aluno a direção da própria aprendizagem" (Santarelli y Santanna, 1998).

Segundo Castells (2000), o poder do novo sistema tecnológico das redes é organizado em uma rede montada em torno de servidores web que usam os protocolos da internet e permitem armazenar e distribuir informações e serviços para qualquer lugar. E complementa que "a lógica do funcionamento de redes, cujo símbolo é a internet, tornou-se aplicável a todos os tipos de atividades, a todos os contextos e a todos os locais que pudessem ser conectados eletronicamente" (p. 89).

Castells (2000, p. 108-109) faz referências a características importantes para o entendimento do paradigma das novas tecnologias da informação e da comunicação com relação a sua capacidade de transformação social. A primeira característica é que a informação é a matéria-prima, "são tecnologias para agir sobre a informação", diferentemente de outras revoluções tecnológicas que ocorreram. A segunda característica é referente "à penetrabilidade dos efeitos das novas tecnologias" que vão moldar os processos de existência individuais e coletivos, interagindo através do novo meio tecnológico. O terceiro aspecto é referente à lógica de redes, onde qualquer sistema ou conjunto de relações usando as novas tecnologias de informação permite a flexibilidade na comunicação, viabilizando um crescimento da rede em detrimento de elementos que estão fora dela.

Uma quarta característica é a flexibilidade, já que os processos são reversíveis e as instituições e organizações podem ser modificadas e alteradas em função da reorganização de seus componentes. Assim, o que "distingue a configuração do novo paradigma tecnológico é sua capacidade de reconfiguração, um aspecto decisivo em uma sociedade caracterizada por constante mudança e fluidez organizacional" (Castells, 2000, p. 109).

Por último, a quinta característica descrita por Castells (2000, p. 109) é a crescente convergência de tecnologias específicas que possibilitam um sistema altamente integrado nos sistemas de informação, influenciando a vida em sociedade. 
As tecnologias de transmissão e conexão das telecomunicações são apenas uma forma de processamento da informação e estão cada vez mais diversificadas e integradas em redes operadas por computadores.

Assim, a tecnologia da informação apresentada por Castells não é um sistema fechado, mas sim uma rede de acesso a múltiplas oportunidades de informação e comunicação contribuindo para uma revolução social.

Para compreender o papel do professor neste modelo de educação a distância pode-se considerar os parâmetros de referência de qualidade definidos pelo MEC. Segundo eles, os professores devem ser capazes de desenvolver um conjunto de ações:

- Estabelecer os fundamentos teóricos do projeto;

- Selecionar e preparar todo o conteúdo curricular articulado a procedimentos e atividades pedagógicas;

- Identificar os objetivos referentes a competências cognitivas, habilidades e atitudes;

- Definir bibliografia, videografia, iconografia, audiografia, tanto básicas quanto complementares;

- Elaborar o material didático para programas a distância;

- Realizar a gestão acadêmica do processo de ensino-aprendizagem, em particular motivar, orientar, acompanhar e avaliar os estudantes;

- Avaliar-se continuamente como profissional participante do coletivo de um projeto de ensino superior a distância" (Brasil, 2007, p. 20).

Considerando os referenciais de qualidade apresentados pelo MEC como competências que os professores devem ter para exercer a docencia a distância (Brasil, 2007) e também observando as referencias propostas por Castells (2000) para o uso das TICs na sociedade moderna, pode-se observar que o uso das tecnologias deve seguir um planejamento apropriado, interdisciplinar - juntamente com as habilidades e competências dos professores - para estimular os alunos a empregá-las na construção do seu conhecimento. 
Ressalta-se que no processo de interação professor-aluno, desenvolvido por meio de Ambientes Virtuais de Aprendizagem - AVAs, é necessária a participação efetiva de todos os atores por meio do compartilhamento de experiências, pesquisas e descobertas. Nesse modelo, o professor é o mediador da aprendizagem e responsável pelo planejamento, desenvolvendo ações e atividades que sejam interessantes e desafiadoras, mas também de acordo com o perfil e nível intelectual dos alunos (Kenski et al., 2009, p. 224).

Aliar a utilização das TICs às salas de aulas de cursos presenciais é um dos objetivos da proposta de utilização dos $20 \%$ a distância em cursos semipresenciais, para estimular a autonomia do aluno e também os recursos digitais. "Na modalidade semipresencial, estudantes e professores estão separados fisicamente em determinados momentos da disciplina, mas interligados por meio das tecnologias de comunicação e interação e dos materiais didáticos empregados. Por tais especificidades, a semipresencialidade torna-se um elemento a mais de flexibilização curricular, no que diz respeito às condições individuais de cada estudante, ao ritmo de aprendizagem, ao local e ao tempo de dedicação aos estudos" (Marchi, Araújo e Istreit, 2008, p. 2).

Uma preocupação a mais é a transição de um curso da modalidade presencial para um modelo híbrido, no qual a maioria das disciplinas continua naquela modalidade e algumas vão passar para o modelo semipresencial. Determinante saber como será conduzida essa alteração no modelo e de que modo essas disciplinas serão ofertadas. "Muitas organizações estão se limitando a transpor para o virtual adaptações do ensino presencial (aula multiplicada ou disponibilizada). Há um predomínio de interação virtual fria (formulários, rotinas, provas, e-mail) e alguma interação on-line (pessoas conectadas ao mesmo tempo, em lugares diferentes). Os cursos são muito empacotados, seguem fórmulas semelhantes, dão ênfase excessiva ao conteúdo e pouca à aprendizagem em pequenos grupos, à pesquisa significativa, à produção de conhecimento adaptado à realidade de cada aluno e grupo" (Moran, 2003, p. 8).

As disciplinas oferecidas na modalidade semipresencial se distinguem por serem organizadas em estrutura modular de ensino e aprendizagem, focada na aprendizagem autônoma do aluno, por se utilizarem da mediação de recursos didáticos organizados em diferentes suportes tecnológicos e por dependerem de esforço para serem desenvolvidas. Elas exigem um planejamento cuidadoso e a organização de um cronograma detalhado, considerando as aulas presenciais e a distância. 
Diante do exposto, observa-se que a profissão docente é complexa e exigente na forma de atuar e se capacitar. Com o desenvolvimento das tecnologias da informação e comunicação, deve ser constante e necessário o esforço para se manter atualizado no domínio e na utilização pedagógica dos recursos digitais.

\section{RESULTADOS E DISCUSSÕES}

Dos treze instrumentos de pesquisa distribuídos, dez foram preenchidos e devolvidos, ou seja, 76,9\% dos sujeitos responderam às indagações propostas. Temse que do curso de Química os cinco questionários distribuídos foram respondidos; e dos oito distribuídos no curso de Pedagogia, cinco docentes devolveram respondidos.

A primeira parte do instrumento de pesquisa é usada para a identificação e caracterização dos respondentes. Considerando o sexo, são sete sujeitos do sexo feminino e três do masculino. Esse dado comprova a tendência, nos cursos de formação de professores, de haver maior número de docentes do sexo feminino. Isso está provavelmente ligado à questão histórica de que o magistério foi atribuição das mulheres e ainda hoje é visto dessa forma por muitas pessoas.

Quanto à titulação dos docentes, 10\% possuem o título de Doutor, 40\% possuem o título de Mestre e os outros 50\% possuem especialização. De acordo com 70\% dos docentes, a opção pelas especializações foi para servir de aperfeiçoamento pessoal e $30 \%$ foram diretamente focadas para o mestrado. No percentual total de respostas sobre a titulação, percebe-se que está sendo cumprido o que a LDB define como exigência mínima de um terço dos docentes possuírem título de mestre ou doutor. $\mathrm{E}$ analisando-se cada curso, observa-se que 60\% dos professores do curso de Química apresentam grau de mestre, enquanto no curso de Pedagogia há um mestre (20\%) e um Doutor (20\%). Mas para a avaliação quanto à legislação, há de se considerar o restante do corpo docente, que não é objeto de avaliação desta pesquisa.

A metade dos respondentes possui mais de cinquenta anos e pode-se considerar que uma parcela significativa (70\%) dos sujeitos possui idade superior a quarenta anos; $30 \%$ dos respondentes estão na faixa de 31 a 40 anos. Nenhum dos docentes que responderam o instrumento está na faixa inicial, de 21 a 30 anos.

Quanto ao tempo de docência universitária, 40\% dos entrevistados possuem mais de 20 anos, seguidos de $30 \%$ que têm de 11 a 20, outros $20 \%$ têm entre cinco e 10 anos e 10\% contam menos de cinco anos de exercício no magistério superior. 
Assim, é um conjunto de profissionais com ampla experiência docente e que podem utilizar estes conhecimentos adquiridos em sala de aula para melhor aproveitar os recursos didáticos e tecnológicos para a transmissão dos conhecimentos aos seus alunos, o que condiz com Tardif e Raymond (2000, p. 217) que escrevem que os saberes dos professores são temporais, pois que são adquiridos e desenvolvidos ao longo da carreira. "O exercício da profissão e seu domínio não ocorrem por uma transferência direta de sabedoria divina. Não se pode supor que um jovem que ingressa como professor na universidade já esteja preparado (mesmo que seja doutor e competente em pesquisa) para enfrentar a docência, ou, não estando, que ele mesmo tome decisões oportunas para estar" (Zabalza, 2004, p. 141).

Outra informação adquirida é que 70\% dos professores participou de cursos de capacitação para a utilização de ferramentas digitais; 20\% não responderam e 10\% que não participaram. A capacitação deles deve ser abrangente, preparando-os para a utilização de recursos tecnológicos que se compõem de vídeos, sons, fóruns, entre outros, além de um ambiente virtual de aprendizagem para ser utilizado como concentrador das ações da disciplina e do curso.

Quanto à capacitação para a utilização de ambientes e técnicas de educação a distância, 60\% afirmaram que foram capacitados e 20\% que não foram, enquanto outros 20\% não responderam. Deve-se ressaltar que essa capacitação é uma etapa importante para a preparação dos docentes que vão atuar nas disciplinas a distância. "É preciso preparar professores e alunos não só para utilizarem esses equipamentos [TICs], de modo que usufruam de suas possibilidades mas, principalmente, que aprendam a fazer intervir o conhecimento, a cultura elaborada, para atribuir significado à informação vinda das mídias. Parece fundamental que tomemos consciência de que, quanto mais se desenvolve a informação e a comunicação, mais competência cognitiva se requer" (Libâneo, 2002, p. 40).

Essa opinião é compartilhada com outros autores que acreditam na necessidade de atualização do docente para utilizar esses recursos no cotidiano da aula a distância. "Uma outra atividade importante nesse momento é a capacitação para o uso das tecnologias necessárias para acompanhar o curso em seus momentos virtuais: conhecer a plataforma virtual, as ferramentas, como se coloca material, como se enviam atividades, como se participa num fórum, num chat, tirar dúvidas técnicas" (Moran, 2004, p. 249).

Segundo Francisco e Machado (2006, p. 6), na elaboração de cursos em Educação a Distância - EAD é necessário oferecer suporte aos professores envolvidos. Esse suporte passa pelo treinamento em tecnologia e na metodologia do 
curso, assessoria para a produção de materiais e acesso a ferramentas apropriadas e também no reconhecimento financeiro e/ou acadêmico do trabalho em EAD. E, no caso analisado, a maioria dos respondentes afirmou que participaram de cursos de formação para atuarem em EAD.

A parte dois do instrumento de pesquisa está dividida em quatro categorias e cada uma delas está subdividida em sete itens. Neste trabalho, será analisada apenas uma categoria. Cada item dela apresenta uma afirmação e foi solicitado ao respondente que valorasse a fase, considerando uma escala de um a cinco, em que o numeral um significa "Nada importante", o dois "Pouco importante", o três indica "neutro", o quatro "Importante" e o número cinco da escala equivale a "Muito importante". Deve-se considerar que algumas frases não foram valoradas em alguns questionários, possivelmente porque o docente não tem uma opinião formada sobre o tema em pauta ou não quer se posicionar.

Para a análise da categoria "A interação entre docentes e estudantes", para esse item, as frases selecionadas estão relacionadas com a comunicação entre os docentes e seus estudantes durante o processo ensino-aprendizagem, considerando a organização e utilização de recursos digitais e os contatos assíncronos mantidos entre as partes em suas aulas a distância. "O Estar Junto Virtual [...] está fundamentada fortemente na exploração das propriedades interativas da tecnologia, promovendo o estabelecimento de uma rede no qual professores e alunos participam ativamente. A comunicação passa a ser multidirecional e é explorada intensamente, pois a participação coletiva, a colaboração e a troca de informações e experiências são caracterizadas pelo forte uso das tecnologias, que abrangem a utilização de muitos recursos como: videoconferência e teleconferência, Internet e ambientes virtuais de aprendizagem, TV, material impresso, software educacionais para web, entre outras mídias digitais" (Schlünzen Junior, 2009, p. 18).

O referencial de qualidade do MEC coloca que o projeto político pedagógico do curso deve explicitar "[...] o sistema de orientação e acompanhamento do estudante, garantindo que os estudantes tenham sua evolução e dificuldades regularmente monitoradas, que recebam respostas rápidas a suas dúvidas, e incentivos e orientação quanto ao progresso nos estudos; [...] valer-se de modalidades comunicacionais síncronas e assíncronas como videoconferências, chats na Internet, fax, telefones, rádio para promover a interação em tempo real entre docentes, tutores e estudantes; [...] facilitar a interação entre estudantes, por meio de atividades coletivas, presenciais ou via ambientes de aprendizagem adequadamente desenhados e implementados para o curso, que incentivem a comunicação entre colegas" (Brasil, 2007, p. 12). 
Seguem as frases apresentadas no instrumento de pesquisa, os números absolutos e os percentuais que os docentes atribuíram a cada valoração.

Para a frase 1, $O$ uso de Ambiente Virtual de Aprendizagem (AVA) é o meio de comunicação entre professor e aluno, os dados coletados são de que $60 \%$ dos discentes consideram importante, 30\% consideram muito importante e $10 \%$ consideram neutra essa situação.

Como a maioria dos sujeitos entrevistados considera de grande importância o uso de AVAs como meio de comunicação, percebe-se sinergia com a literatura pesquisada, sobre a utilização desses ambientes que "os alunos podem interagir com os professores e com os colegas em chats e fóruns de discussão. Podem ainda desenvolver as suas atividades, quer sejam apresentações, teses ou exercícios individuais ou em grupo, com a possibilidade de serem enviadas imediatamente para o professor ou para os participantes do curso. Os alunos podem fazer comentários sobre as atividades [...] os professores podem fazer comentários sobre as atividades entregues, assim como retornar comentários e solicitações" (Parreira Júnior, 2010, p. 82-83).

A utilização do AVA ajuda o professor na gestão da sua sala de aula a distância, pois seus recursos permitem a distribuição do material instrucional, a comunicação através de fórum, o recebimento das atividades desenvolvidas pelos alunos, assim como o feedback do professor a essas atividades.

A frase 2, $O$ aluno comunica-se com o professor através de email e fórum de discussão, para a maioria dos respondentes (70\%) é importante, para 20\% é muito importante e somente $10 \%$ consideram-na uma situação neutra.

Nas disciplinas presenciais, o aluno pode solicitar uma explicação no momento em que o professor explica a matéria ou resolve um exercício. Na educação a distância, há o inconveniente da distância ou mesmo da questão temporal. Assim, é necessária a utilização de ferramentas que permitam a comunicação atemporal, como o e-mail ou o fórum. "Ferramenta de correspondência pessoal (um para um). A agilidade é sua maior riqueza para a EAD. Como as mensagens de correio eletrônico chegam ao destinatário quase imediatamente, são preciosas para manter contato freqüente e ágil com os alunos. É comum que o estudante da modalidade a distância estude sozinho e de forma solitária. A referência humana que tem está, em geral, no tutor a distância. É primordial que suas demandas sejam respondidas com presteza, que ele perceba o tutor tão próximo quanto possível. As demandas por correio eletrônico devem ser respondidas não só com agilidade como com atenção pessoal. É um meio 
de contato individualizado em que o aluno pode colocar suas questões de forma privada e particular" (Tornaghi, 2006, p. 169).

Comparando o quantitativo das avaliações das frases 1 e 2 dessa categoria, quando 90\% dos respondentes consideram importante ou muito importante a comunicação através do AVA e/ou através de e-mail e fórum. Percebe-se que para esses docentes a interação aluno-professor é fundamental para o desenvolvimento da disciplina e o consequente atendimento às ocorrência no momento do aprendizado.

Para a frase 3, Retornar os questionamentos dos alunos postados no AVA ou Fóruns e e-mail, 70\% dos docentes qualifica como muito importante, 20\% importante e $10 \%$ neutra.

A tarefa de retornar os questionamentos dos alunos e também o feedback das atividades entregues por eles foi considerada de grande importância por parte dos docentes e pode-se observar na pesquisa desenvolvida por Quevedo (2008, p. 18) que anota que "a menção da ausência de feedback imediato por parte do professor foi percebido como um aspecto negativo para a experiência".

Para a frase 4, Manter uma presença freqüente no AVA, os dados coletados são de que $70 \%$ dos respondentes a consideram muito importante e $20 \%$ importante, enquanto para $10 \%$ é neutra. Ter uma presença no ambiente é importante para observar as ações dos alunos e ter condições de responder em tempo hábil aos questionamentos e dúvidas apresentados, assim como observar as ausências e desenvolver ações para reparar estas atitudes.

É fundamental para os respondentes a participação frequente no ambiente, e isso se traduz na qualificação apresentada a frase. Os alunos sentem-se apoiados e essa avaliação é equivalente à avaliação da frase anterior sobre o feedback aos alunos. "Es muy importante lo que denominan "crear una presencia a distancia" si se desea mantener el interés de todos los estudiantes (especialmente los remotos), para lo que no sólo es preciso desarrollar habilidades de comunicación sino contemplar las estrategias instructivas adecuadas" (Arrufat, 2008, p. 8).

A frase 5, Entrar em contato com os alunos que estão ausentes do AVA, Fóruns e e-mail, é uma ação muito importante para 70\% e para $20 \%$ é importante, enquanto para 10\% é uma situação neutra. E na EAD é a forma de buscar o aluno que está com algum problema, o qual, seja por dificuldade de entendimento ou falta de organização, não está acompanhando a disciplina. 
É necessário estimular o aluno para a retomada das atividades e isso é possível via contatos utilizando-se os recursos do AVA, quer sejam fóruns ou mesmo e-mail. $\mathrm{Na}$ aula presencial, o professor vai notar o desinteresse do aluno pelos sinais que emite ao longo da aula, quee seja não prestando atenção, desenvolvendo outras atividades e mesmo conversando com os colegas. Como na aula virtual não é possível essa análise, é necessário observar as participações e entregas de atividades.

Para a frase 6, Flexibilização da aprendizagem no tempo e espaço, 80\% dos docentes responderam que é muito importante e $10 \%$ consideraram-na neutra, enquanto $10 \%$ não mensurou a frase. Segundo Schlünzen Junior, o processo de ensino e aprendizagem na EAD passou a ser mediado por tecnologias digitais e os alunos estão separados espacial e/ou temporalmente. E acrescenta que: "o fator espaço e tempo são determinantes, pois os sujeitos participantes desta modalidade de educação não compartilham do mesmo espaço e, não necessariamente, do mesmo tempo. A questão tempo caracteriza o que nesta modalidade denomina-se de atividades síncronas ou assíncronas e que são definidas e realizadas de acordo com a proposta pedagógica do curso" (Schlünzen Junior, 2009, p.17). "[A flexibilização do tempo e do espaço] possibilita a realização das atividades da disciplina em horário e local mais apropriado ao acadêmico, em especial àquele já inserido no mercado de trabalho, reduzindo as horas de deslocamento até a universidade e possibilitando o cumprimento das atividades, de acordo com a necessidade e característica de cada aluno" (Marchi, Araújo e Istreit, 2008, p.3).

Para a frase 7, Trabalhos desenvolvidos em grupo, os dados coletados informam que $50 \%$ dos docentes consideram importante, 20\% mensuraram como muito importante e 30\% consideraram neutra a situação. Afirma Kenski (2008) que na educação online a colaboração é peça chave para a construção do conhecimento individual e também coletivo, que é compartilhado pela maioria dos docentes participantes da pesquisa, e acrescenta que: "o ato de colaborar pode favorecer a aprendizagem, pois agrega novas oportunidades e possibilidades não enxergadas de forma individual em determinado momento. As novas tecnologias de informação e comunicação contribuem para esse cenário, pois favorecem as interações na medida em que viabilizam oportunidades de comunicação entre pessoas dispersas geograficamente, com diferentes disponibilidades de tempo para acesso às informações e para encontros presenciais com seus pares” (p. 21).

Após a exposição da análise e interpretação das frases da categoria $A$ Interação Entre Docentes e Estudantes, nota-se que há uma escolha maior para a opção muito importante na escala de valoração por parte dos respondentes e ainda uma segunda opção bem considerada e também significativa que é o importante e há 
uma valoração para a opção neutra em cada frase, exceto para a frase sete que há três valorações (S7 optou pela valoração neutra em quatro frases), e não há nenhum voto para a opção pouco importante ou nada importante. Há se de considerar que um sujeito da pesquisa (S10) não valorou uma frase (seis) dessa categoria, possivelmente por não ter uma opinião formada sobre o tema em pauta ou não querer se posicionar. "Neste sentido, professores e alunos assumem diante disso, papéis importantes e que definem suas ações nesta modalidade de educação. Para os professores, evidentemente além de conhecedores de conteúdo, a importância da mediação pedagógica, a função de propor atividades que envolvam os alunos em um processo reflexivo que possibilita um trabalho colaborativo e investigativo. Além de fornecer múltiplas fontes de informação, de mediar um processo de aprendizagem que privilegie a construção do conhecimento do aluno e uma avaliação formativa, de oportunizar e explorar os diferentes contextos e experiências dos aprendizes, de estar atento a participação do aluno nos ambientes virtuais e de saber acolhe-lo, entendendo que o aluno a distância encontra-se, evidentemente, distante, muitas vezes "solitário", com dificuldades" (Schlünzen Junior, 2009, p. 20).

Imprescindível o planejamento para a utilização das TICs na interação entre docentes e discentes, para que não ocorra uma dispersão do esforço de comunicação e que possa ser utilizada para a efetivação da construção do conhecimento por parte do aluno. "Os recursos tecnológicos nada significam em si, nada fazem por si sós. Eles precisam estar a serviço de um projeto pedagógico claro. Seu uso precisa ser planejado de forma sistêmica e estar aliado a outros recursos. Seu papel é limitado e, afora atividades de curta duração e/ou pequena abrangência conceitual, deve estar aliado ao uso de outros meios" (Tornaghi, 2006, p. 170).

Logo, a tecnologia digital deve estar a serviço da construção do conhecimento e para isso, a preparação e a utilização dos recursos comunicacionais deve ter ênfase na interação que melhor atende aos propósitos da disciplina.

\section{CONSIDERAÇÕES FINAIS}

Considerando-se os dados coletados com o instrumento de pesquisa, pode-se observar que na categoria A Interação Entre Docentes e Estudantes, em que as sete frases afirmativas permitiram considerar que os professores respondentes entenderam e utilizam os recursos digitais para efetivar a interação com os alunos. Analisou-se a utilização dos AVAs e demais mecanismos de comunicação síncronos e assíncronos, a forma de solicitar atividades e como as respostas eram apresentadas e como isso pode contribuir para o aprendizado do aluno. 
Como as aulas não são presenciais, os documentos oficiais, principalmente o referencial de Qualidade, indicam a necessidade de utilização de outros recursos para a comunicação entre docente e discente e cita alguns. E é fundamental a sua utilização tanto para apresentação de conteúdo programático como para atender as dúvidas dos alunos e também para apresentar respostas e feeedback das atividades.

Transformar um curso presencial em semipresencial é uma ação que deve ser planejada e que requer uma dedicação de todo o grupo, desde a coordenação e docentes até os técnicos e a administração, pois há muitas alterações a serem desenvolvidas para atender aos requisitos definidos na legislação.

Apresentaram uma opinião positiva, afirmando que há uma interação professor e aluno por meio das comunicações assíncronas, pois deve ser considerado que o grupo continua a ter aulas presenciais toda semana quando ocorre a comunicação síncrona. $\mathrm{E}$ as dúvidas e comentários podem ser realizados pessoalmente.

Ressalte-se que o desenvolvimento tecnológico atual permitiu a utilização de ferramentas digitais e a criação de ambientes virtuais de aprendizagem. Esses ambientes caracterizam-se por permitir a organização da informação e as atividades a serem desenvolvidas pelos alunos e professores, assim como por oferecer recursos de comunicação e interação entre os participantes. Kenski (2005, p.8) escreve que nos AVAs os alunos acessam textos, desenhos, fotos, animações, sons e vídeos, assim como podem interagir com professores e colegas em chats e fóruns de discussão. Também podem entregar as atividades individuais e coletivas a qualquer momento e os professores contribuir com comentários bem como os alunos; e assim, pode-se criar um clima de cooperação em que todos contribuem para a aprendizagem da turma.

Este trabalho pode contribuir com a discussão, posicionando que a apresentação de um assunto de forma presencial não pode ser explorada da mesma forma que na modalidade a distância. Sua transposição para o virtual necessita de um planejamento cuidadoso, observados os objetivos pedagógicos a serem alcançados, a disponibilidade de recursos tecnológicos.

É consenso que o planejamento e a execução das disciplinas remodeladas de presencial para a distância necessitam de novos parâmetros bem mais complexos do que a simples transposição da prática anteriormente utilizada para o ambiente digital, sendo necessária uma nova preparação, com novos conceitos e atitudes para o relacionamento docente-discente. 


\section{REFERÊNCIAS BIBLIOGRÁFICAS}

Arrufat, M. J. G. (2008). Comunicación didáctica del docente universitario en entornos presenciales y virtuales. Revista Iberoamericana de Educación, 46 (1).

Barros, S. (2009). O uso da tecnologia no cotidiano escolar. En Teixeira, G. F. M. E.; Miranda, A. A. B. (Org.). Seminário nacional uno e o diverso na educação escolar, 10, Uberlândia: Anais. Edufu.

Brasil (2007). Referenciais de qualidade para educação superior a distância. Diário Oficial [da] Republica Federativa do Brasil. Brasília, DF.

Castells, M. (2000). A sociedade em rede, 1 (8). Editora Paz e Terra.

Cicillini, G. A. (2010). Professores universitários e a sua formação: concepções de docência e prática pedagógica. En Novaes, G. S.; Cicillini, G. A. (Orgs.). Formação docente e práticas pedagógicas: olhares que se entrelaçam. Araraquara: Junqueira y Marin; Belo Horizonte: FAPEMIG.

Delors, J.; et al. (1998). Educação: um tesouro a descobrir. São Paulo: Cortez; Brasília: UNESCO.

Francisco, D. J.; Machado, G. J. C. (2006). Sociedade, EAD, inclusão e formação de professores. Revista Iberoamericana de Educacion, 38 (1). Madrid.

Goldenberg, M. (1997). A arte de pesquisar: como fazer pesquisa quantitativa em ciências sociais. Rio de Janeiro: Record.

Gomes, R. (1994). A análise de dados em pesquisa qualitativa. En Minayo, M. C. S. (Org.). Pesquisa social: teoria, método e criatividade. Petrópolis: Vozes.

Kenski, V. M. (2008). Novos processos de interação e comunicação no ensino mediado pelas tecnologias. Cadernos de Pedagogia Universitária, 7. São Paulo: USP.

Kenski, V. M. (2006). Gestão e uso das mídias em projetos de educação a distância. Revista e-curriculum, 1 (1). São Paulo

Kenski, V. M.; et al.(2009). Ensinar e aprender em ambientes virtuais. Educação Te- mática Digital. Campinas, 10 (2), (223249).

Lessard, C.; Tardif, M. (2008). As transformações atuais do ensino: três cenários possíveis na evolução da profissão de professor? En Tardif, M.; Lessard, C. (Org.). $O$ ofício de professor: história, perspectivas e desafios internacionais. Petrópolis: Vozes.

Libâneo, J. C. (2002). Didática: velhos e novos temas. Edição do autor.

Maia, C.; Mattar, J. (2007). ABC da EAD. São Paulo: Pearson Prentice Hall.

Malhotra, N. K. (2004). Pesquisa de marketing: uma orientação aplicada. (4 ed.). Porto Alegre: Bookman.

Malusá, S. E.; Silva, V. A. (2007). Saberes e formação pedagógica: pensando a prática da docência universitária. En Fonseca, S. G. (Org.). Currículos, saberes e culturas escolares. Campinas: Alínea.

Marchi, A. C. B.; Araújo, D. D.; Istreit, I. R. (2008). Modalidade semipresencial de ensino: alguns resultados da implantação em disciplinas de graduação da UPF. Revista novas tecnologias na educação. Porto Alegre, 6 (2), CintedUFRGS.

Moran, J. M. (2004). Os novos espaços de atuação do educador com as tecnologias. En Romanowski, J. P.; et al. (Org.). Conhecimento local e conhecimento universal: diversidade, mídias e tecnologias na educação, 2, Curitiba: Champagnat.

Moran, J. M. (2003). Educação inovadora presencial e a distância. [en línea] Disponível em: http://www.eca.usp.br/ prof/moran/inov 1.htm [consulta 2012, 19 de agosto].

Moroz, M.; Gianfaldoni, M. H. T. A. (2006). O processo de pesquisa: iniciação, 2. Brasília: Líber Livro Editora.

Nóvoa, A. (2008). Os professores e o novo espaço público da educação. In: Tardif, M.; Lessard, C. (Org.). O ofício de professor: 
história, perspectivas e desafios internacionais. Petrópolis: Editora Vozes.

Parreira Júnior, W. M. (2010). O Docente e a educação a distância. En Novaes, G. S.; Cicillini, G. A. (Orgs.). Formação docente e práticas pedagógicas: olhares que se entrelaçam. Araraquara: Junqueira \& Marin; Belo Horizonte: FAPEMIG.

Quevedo, A. (2011). O ensino semipresencial, do ponto de vista do aluno. E-curriculum, 7 (1). São Paulo [en línea] Disponível em: http://revistas.pucsp.br/index. php/curriculum [consulta 2012, 19 de agosto]

Santarelli, D.; Santanna, S. (1998). Feitos e efeitos: Informática na Escola. São Paulo - SP, Berkeley Brasil.
Schlunzen Junior, K. (2009). Educação a distância no Brasil: Caminhos, políticas e perspectivas. Educação Temática Digital, 10 (2). Campinas, (16-36).

Tardif, M.; Raymond, D. (2000). Saberes, tempo e aprendizagem do trabalho no magistério. Educação \& Sociedade, v.21, n.73, dez. (209-244). ISSN: 0101-7330.

Tornaghi, A. (2006). Computadores, internet e educação a distância. En Secretaria de Educação a Distância (Org). Tecnologias na educação de professores a distância. Brasília: MEC. (166-170).

Zabalza, M. A. (2004). O ensino universitário: seu cenário e seus protagonistas. Porto Alegre: Artmed.

\section{PERFIL ACADÊMICO E PROFISSIONAL DOS AUTORES}

Walteno Martins Parreira Júnior. Mestre em Educação pela Universidade Federal de Uberlândia - UFU, professor da Fundação Educacional de Ituiutaba FEIT, associada à Universidade do Estado de Minas Gerais - UEMG. Membro do grupo de pesquisa "Desenvolvimento profissional e docência universitária: saberes e práticas educativas” do Programa de Pós-Graduação em Educação - PPGEd-UFU.

E-mail: waltenomartins@yahoo.com

Silvana Malusá Baraúna. Doutora em Educação pela Universidade Metodista de Piracicaba - Unimep, professora da Faculdade de Educação da UFU, coordenadora do grupo de pesquisa "Desenvolvimento profissional e docência universitária: saberes e práticas educativas" - PPGEd-UFU.

E-mail: malusa@faced.ufu.br

Guilherme Saramago de Oliveira. Doutor em Educação pela UFU, professor da UFU, membro do grupo de pesquisa "Desenvolvimento Profissional e Docência Universitária: saberes e práticas educativas" - PPGEd-UFU.

E-mail: gsoliveira@ufu.br 
DIRECCIÓN POSTAL DE LOS AUTORES

\author{
Walteno Martins Parreira Júnior \\ Rua Manoel Ascenso Batista, 858 \\ Bairro Santa Mônica - Uberlândia - MG \\ Brasil \\ CEP: 38408-292
}

Fechas de recepción del artículo: 28/10/12

Fecha de aceptación del artículo: 14/04/13

\title{
Como citar este artículo:
}

Parreira Júnior, W. M.; Malusá Baraúna, S.; Saramago de Oliveira, G. (2013). Docencia universitária: um estudo sobre a interação entre docentes e estudantes em cursos na modalidade semipresencial. RIED. Revista Iberoamericana de Educación a Distancia, volumen 16, $\mathrm{n}^{\circ} 2$, pp. 193-212. 